\title{
QUANTIFICAĢ̃̃O DE MICROPLÁSTICOS EM PRAIAS ANTROPIZADAS E POUCO ANTROPIZADAS NO LITORAL DO RIO GRANDE DO SUL, BRASIL
}

\author{
Quantification of microplastics on anthropized and little \\ anthropized beaches in Rio Grande do Sul coast, Brazil
}

\author{
Ingrid Schneider ${ }^{1}$, Daiana Maffessoni ${ }^{2}$ \\ 1 Universidade Estadual do Rio Grande do Sul. E-mail: ingschneider@hotmail.com \\ 2 Universidade Estadual do Rio Grande do Sul. E-mail: mafadaia@gmail.com
}

\begin{abstract}
RESUMO
Este estudo analisou a presença de microplásticos no sedimento arenoso em três praias no litoral norte do Rio Grande do Sul - Sul do Brasil, com diferentes níveis de antropização. As praias de Torres e Capão da Canoa são mais urbanizadas que a Praia das Cabras (Cidreira). A amostragem foi realizada ao longo das quatro estações do ano. Em cada localidade, foram amostradas seis parcelas quadradas $(0,5 \times 0,5 \mathrm{~m})$, incluindo três pontos na marca da preamar e três pontos na base das dunas. A presença de microplásticos foi registrada em todas as amostras. No total, foram coletados 1.727 microplásticos (886 unidades de fragmentos e 841 unidades de pellets). A Praia das Cabras apresentou maior concentração de microplásticos (1.083 unidades) do que as praias urbanizadas: Capão da Canoa (482 unidades) e Torres (162 unidades). Além disso, foi encontrada grande quantidade de pellets na Praia das Cabras, enquanto as outras duas praias apresentaram maior acúmulo de fragmentos. O maior acúmulo de microplásticos foi encontrado durante a primavera (687 unidades), seguida pelo inverno (462 unidades), verão (410 unidades) e outono (168 unidades). A presença de microplásticos em praias arenosas parece não estar relacionada somente à urbanização, mas também à interação continente-oceano.
\end{abstract}

Palavras-chave: sedimento, praia, urbanização, microplásticos.

Recebido em: 07/01/2020

Aprovado em: 16/11/2020

Publicado online em: 20/05/2021 


\section{ABSTRACT}

This study analyzed the presence of microplastics in the sediment of the three sandy beaches, in the North Coast of Rio Grande do Sul - southern Brazil, with different levels of anthropization. The beaches of Torres and Capão da Canoa are more urbanized than Praia das Cabras (Cidreira). The sampling was carried out along the four seasons of the year. In each locality, six square plots $(0,5 x$ $0,5 \mathrm{~m}$ ) were sampled, including three points at high tide mark and three points at the base of the dunes. The presence of microplastic was recorded in all samples. In total, 1.727 microplastics were collected (886 fragment units and 841 pellet units). Praia das Cabras showed a higher concentration of microplastic (1.083 units), than the urbanized beaches: Capão da Canoa (482 units) and Torres (162 units). In addition, a large amount of pellets was found in Praia das Cabras, whereas the other two beaches showed a greater accumulation of fragments. The highest accumulation of microplastic was found during spring (687 units), followed by winter (462 units), summer (410 units) and autumn (168 units). The presence of microplastics in sandy beaches seems not be related only to urbanization, but also to the continent-ocean interaction.

Keywords: sediment, beach, urbanization, microplastics.

\section{INTRODUÇÃO}

O plástico está cada vez mais presente no cotidiano da sociedade. É utilizado em uma ampla variedade de produtos devido à sua versatilidade e a seu baixo custo de fabricação (Jambeck et al., 2015; Lebreton et al., 2017; Law, 2017). Entre 1950 e 2017, a produção global de plástico passou de 1,5 para 348 milhões de toneladas por ano (Plastics Europe, 2018). Se a produção e o gerenciamento dos resíduos seguirem a tendência atual, Geyer, Jambeck e Law (2017) estimam que, até 2050, 12 milhões de toneladas de plástico vão acabar em aterros ou no meio ambiente.

Esse aumento da fabricação e do uso do plástico tem acarretado sua onipresença na natureza (Law, 2017). Nos oceanos, a poluição por plástico constitui a maior parte do lixo encontrado (Galgani; Phan \& Reisser, 2017) e representa uma ameaça eminente à biota marinha e à oferta de bens e serviços ecossistêmicos (Gall \& Thompson, 2015). A entrada desses resíduos no ambiente marinho deriva principalmente de fontes terrestres através dos rios (Lebreton et al., 2017) e locais próximos à costa (Jambeck et al., 2015), porém também de atividades marítimas, como, por exemplo, pela perda ou pelo descarte por embarcações de pesca, navios comerciais e plataformas (Galgani; Hanke \& Maes, 2015). Embora os primeiros relatos da poluição nos oceanos por itens grandes de plástico datem de 1960 e início de 1970 (Holgersen, 1961; Caldwell; Caldwell \& Siebenaler, 1965; Brongersma, 1968; Carpenter \& Smith, 1972; Gomes, 1973), nas últimas décadas, um poluente emergente, denominado microplástico (MP), também tem recebido atenção (Andrady, 2015).

Os MPs são definidos como partículas de plástico inferiores a $5 \mathrm{~mm}$ (Arthur; Baker \& Bamford, 2009) e podem ser classificados como primários ou secundários, dependendo de sua fonte de origem (Barnes et al., 2009; Avio; Gorbi \& Regoli, 2016). Materiais fabricados com dimensões inferiores a $5 \mathrm{~mm}$, como as esférulas plásticas (pellets), utilizadas para a produção de materiais poliméricos, e as partículas de plástico, usadas em produtos de higiene pessoal (esfoliantes e pastas de dente, por exemplo), são definidos como MPs primá- 
rios e chegam ao ambiente marinho por derramamentos acidentais durante a sua cadeia produtiva e através de descargas de águas residuais (Ziajahromi et al., 2017; Andrady, 2017; Castro; Silva \& Araújo, 2018). Já os MPs secundários resultam de objetos plásticos que se fragmentam em pedaços menores, por processos físicos e químicos de degradação, como a fotodegradação e abrasão física (Moore, 2008; Cole et al., 2011; Andrady, 2011; Ivar do Sul, 2014).

A presença dos MPs tem sido documentada em diferentes ambientes: no sedimento de praias arenosas (Hengstmann et al., 2018) e de águas profundas (Van Cauwenberghe et al., 2015), nos giros oceânicos subtropicais (Brach et al., 2018) e em regiões remotas da Antártica (Waller et al., 2017) e do Ártico (Peeken et al., 2018). A ingestão desses MPs pela biota já foi relatada na literatura científica e tem afetado uma ampla diversidade de organismos, desde tartarugas (Camedda et al., 2014; Nicolau et al., 2016; Pham et al., 2017), aves (English et al., 2015; Ryan, 2015; Wilcox; van Sebille \& Hardesty, 2015), peixes (Ory et al., 2017), mamíferos marinhos (Lusher et al., 2015) até espécies pequenas, como o zooplâncton (Cole et al., 2013), causando efeitos fisiológicos e comportamentais deletérios. Também ameaçam a biodiversidade, pois podem servir de substrato e vetor para a dispersão de espécies exóticas (Reisser et al., 2014).

Após a entrada dos plásticos nos oceanos, o vento, as marés e as correntes contribuem para a sua dispersão, transportando-os por longos períodos e para longe da sua fonte de origem (Barnes et al., 2009; Brown; Galloway \& Thompson, 2010; Falcão \& Souza, 2014; Critchell \& Lambrechts, 2016). Em regiões costeiras, além desses fatores, a geomorfologia costeira e as ressacas podem influenciar significativamente os padrões de acumulação do plástico nas praias (Falcão \& Souza, 2014; Lozoya et al., 2016), assim como a proximidade de fontes emissoras, como as regiões portuárias, rotas comerciais e áreas urbanas (Barnes et al., 2009).

O sedimento de praias é um dos ambientes mais estudados quanto à poluição por MPs (Pinheiro et al., 2019). Regiões costeiras densamente urbanizadas são reconhecidas como uma fonte terrestre de contaminação e têm sido estudadas no mundo todo (Coley \& Verbel, 2015; Nel et al., 2016; Lozoya et al., 2016; Antunes; Frias \& Sobral, 2018), embora áreas sem ação antrópica também apresentem significativo acúmulo (Baztan et al., 2014; Alomar; Estarellas \& Deudero, 2016), demonstrando a sua ampla dispersão pelos ambientes costeiros e marinhos. No Rio Grande do Sul (RS), os estudos sobre MPs em praias e o impacto em animais marinhos são bem documentados para a região sul do estado (Zarzur, 1995; Santos et al., 2004; Tourinho, 2007; Alencar; Proietti \& Rodrigues, 2017; Macedo et al., 2018). No entanto, para o litoral norte, região caracterizada pela intensa urbanização (Lopes; Ruiz \& Anjos, 2018), há somente dois trabalhos sobre pellets (Gomes, 1973; Pianowski, 1997), um estudo sobre fragmentos (Portz; Manzolli \& Ivar do Sul, 2011) e outro sobre a ingestão de detritos por tartarugas marinhas (Rigon, 2012). Dessa forma, não há estudos comparando áreas urbanizadas e não urbanizadas no RS.

Devido à carência de pesquisas sobre a temática no âmbito do litoral norte do RS, este estudo analisou a presença de microplásticos no sedimento arenoso em três praias do litoral norte: Capão da Canoa, Torres - Praia Grande - e Praia das Cabras (Cidreira). Os objetivos foram a avaliação do quantitativo e a caracterização quanto ao tipo (pellets ou fragmentos) predominante nas áreas de estudo; se há diferença entre as praias urbanizadas (Capão da Canoa e Torres) e não urbanizadas (Praia das Cabras); e a influência da sazonalidade e das condições oceanográficas na deposição dos MPs. 


\section{MATERIAL E MÉTODOS}

\section{Área de estudo}

As áreas de estudo são praias de sedimento arenoso, localizadas na planície costeira do RS, no litoral norte do estado, sendo elas: Capão da Canoa, Torres - Praia Grande - e Praia das Cabras (Cidreira) (Figura 1). A escolha dessas praias para coleta se deve ao fato de a Praia das Cabras, no munícipio de Cidreira, ser uma praia pouco antropizada, fazendo um contraponto com as praias de Capão da Canoa e Torres, que são praias altamente urbanizadas no litoral norte gaúcho.

Na Praia das Cabras há reduzida ação antrópica e onde se encontra uma das últimas remanescentes de dunas ativas e conservadas da região do litoral norte do RS (Oliveira et al., 2017). A Praia Grande, localizada em Torres, recebe um grande público na temporada, passando de 37.702 durante o inverno para mais de 60 mil pessoas durante o verão, o que representa um aumento de 72,9\% (Zuanazzi \& Bartels, 2016). Capão da Canoa possui a maior população do litoral norte e, assim como Torres, também é uma cidade marcada pelo crescimento populacional no verão. Estima-se que passe dos 47.538 habitantes para 106.399 nessa época, correspondendo a um crescimento de 123,8\% (Zuanazzi \& Bartels, 2016).

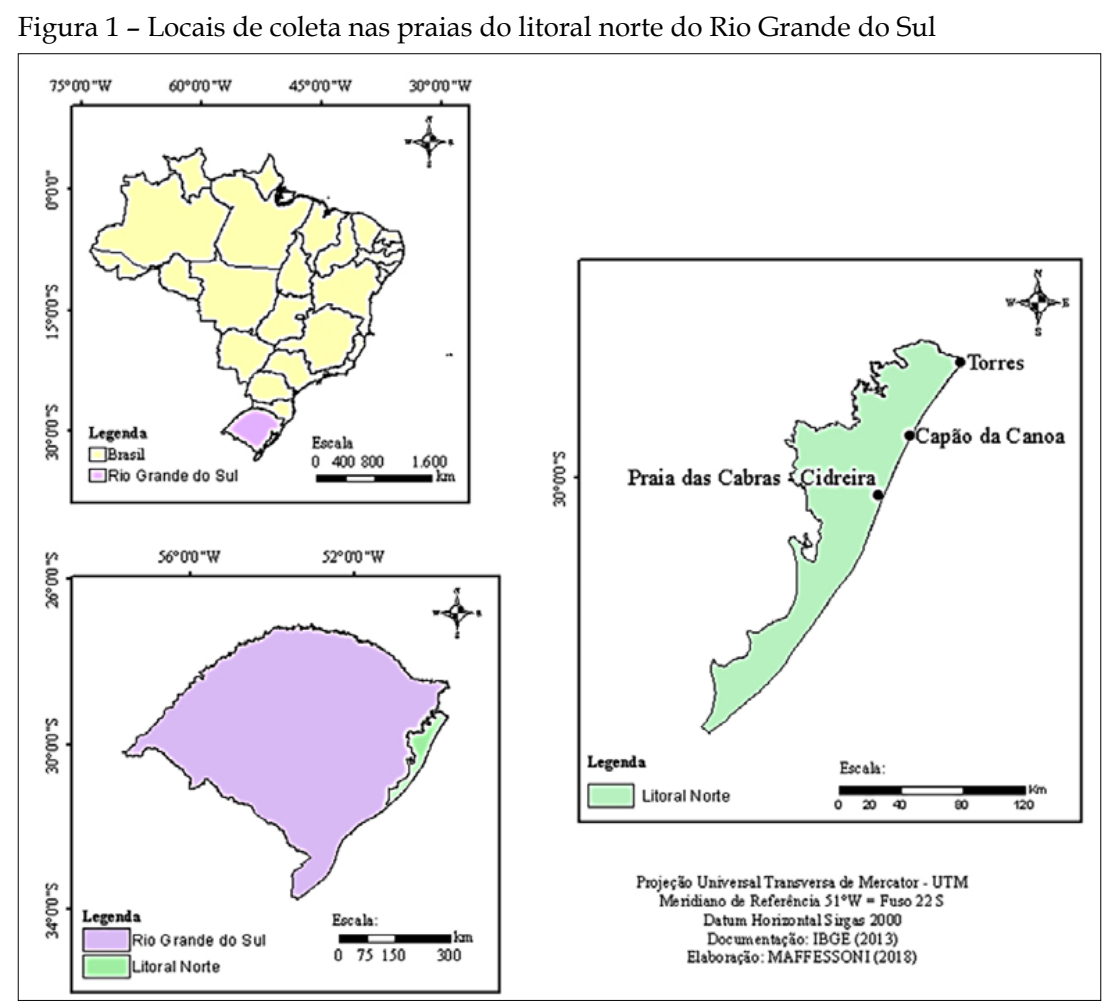

\section{Planície costeira}

A Planície Costeira do Rio Grande do Sul, em seus 620 km de costa arenosa, é delimitada ao sul pela desembocadura do Arroio Chuí e ao norte pela desembocadura do rio Mampituba, em Torres. Caracteriza-se como uma linha de costa aberta, retilínea e sem reentrâncias, com orientação NE-SW (Tomazelli \& Villwock, 1992). A morfologia da plataforma continental, o regime de micromarés e a altura das ondas em torno de 1,5 $\mathrm{m}$ tornam 
a planície costeira uma barreira dominada por ondas. Com exceção de Torres, que suas "formações rochosas são constituídas de arenitos, basaltos e sequências vulcano-clásticas, que lhe conferem um pequeno grau de proteção à dinâmica costeira" (Calliari et al., 2006), as demais praias estão totalmente expostas à energia do ambiente marinho.

O sedimento arenoso é de granulometria fina e as praias se comportam, na maior parte do tempo, como dissipativas e intermediárias (Wright \& Short, 1984). A praia de Torres caracteriza-se como praia do tipo intermediário, de mobilidade moderada a alta, devido a grandes variações verticais e, por predominar estágios intermediários, torna a praia suscetível à erosão. Enquanto Capão da Canoa encontra-se em estágio morfodinâmico dissipativo e intermediário, com mobilidade moderada a alta, a Praia das Cabras apresenta-se como intermediária e de baixa mobilidade (Calliari et al., 2006; Reichow, 2018). A deriva litorânea de sedimentos é predominante de SW-NE (Figueiredo \& Calliari, 2006).

\section{Coleta das amostras e classificação}

A metodologia utilizada para o presente estudo é adaptada da pesquisa realizada por Frias et al. (2018). As coletas nas praias de Torres, Capão da Canoa e Cabras foram realizadas nas quatro estações do ano de 2018: verão (janeiro), outono (maio), inverno (julho e agosto) e primavera (outubro).

As coletas foram realizadas em triplicata, sendo as amostras coletadas na marca da preamar e na base das dunas. Em cada ponto de coleta, com o uso de um quadrante $(0,5 \times$ $0,5 \mathrm{~m})$, retiraram-se os dois primeiros centímetros de areia com o auxílio de uma pá. As amostras foram acondicionadas e identificadas, conforme a praia e o local de coleta. A escolha desse tipo de amostragem superficial é para observar a deposição recente dos MPs nas praias, a fim de identificar os possíveis fatores que podem influenciar na sua distribuição, pois a ação dos ventos, das marés e das ressacas também contribui para o transporte de detritos ao longo da praia e o acúmulo a longo prazo no pós-praia (Silva, P.P.G e, 2016; Gregoy, 2009; Turra et al., 2014; Andrade Neto, 2014).

No laboratório, de acordo com a metodologia de Ivar do Sul, Costa e Fillmann (2017), cada amostra foi seca em estufa a $100^{\circ} \mathrm{C}$ e, após a secagem, peneirada com peneiras granulométricas com malhas de $1 \mathrm{~mm}$ e 4,75 mm. Com o auxílio de uma lupa binocular, o material retido foi separado e os MPs classificados em dois tipos de plástico: fragmentos de plástico (Figura 2a) e pellets (Figura 2b).

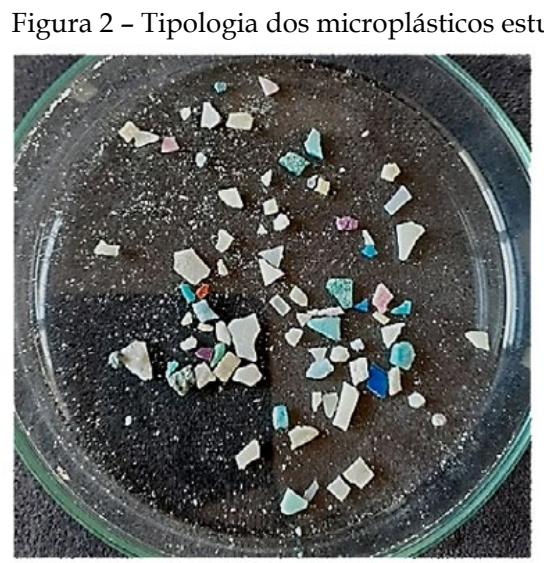

a

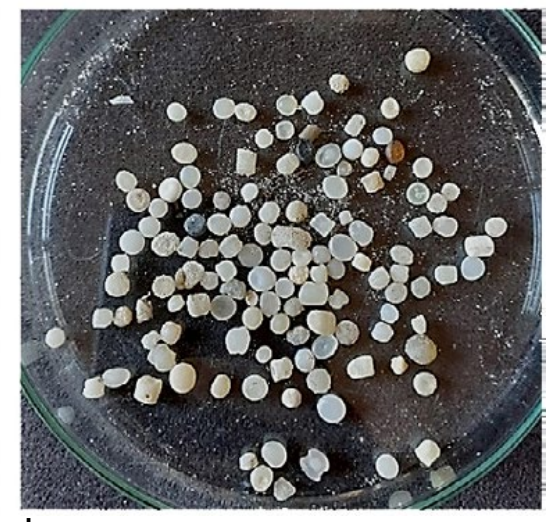

b 


\section{Análise de dados}

Os dados da quantidade de pellets e fragmentos foram analisados quanto à praia (Cabras, Capão da Canoa e Torres), a região (preamar e base das dunas) onde foram encontrados e a estação do ano (primavera, verão, outono e inverno). Para complementar as análises sazonais, as condições oceanográficas, como a altura das ondas, a direção dos ventos e das ondas também foram analisadas nos dias de coleta, utilizando os dados da plataforma Windy.

A análise estatística dos dados obtidos em cada região, em triplicata, foi realizada no software R. Inicialmente, realizou-se o teste de linearidade dos dados, onde se geraram os modelos exploratórios de resíduos e foi feita a transformação mais extrema dos dados $\log (x+1)$ em busca da linearidade, visto que o número de amostras (n) é elevado. Posteriormente, procedeu-se com teste de Anova (análise de variância) de dois fatores (praia e região - preamar e base das dunas) para a verificação de diferenças na presença de pellets, fragmentos e totais. Havendo diferenças entre os níveis, realizou-se teste Post-hoc, Student-Newman-Keuls (SNK) para identificação das diferenças. Foi considerado nível de significância de $5 \%$.

\section{RESULTADOS E DISCUSSÃO}

\section{Avaliação quali-quantitativa}

No sedimento arenoso das três praias estudadas foram coletados 1.727 microplásticos (MPs), sendo 886 unidades (un.) de fragmentos e 841 un. de pellets. A praia que apresentou maiores quantidades de MPs foi a não urbanizada, a Praia das Cabras, com 1.083 un., seguida por Capão da Canoa, com 482 un., e Torres, com 162 un. (Figura 3).

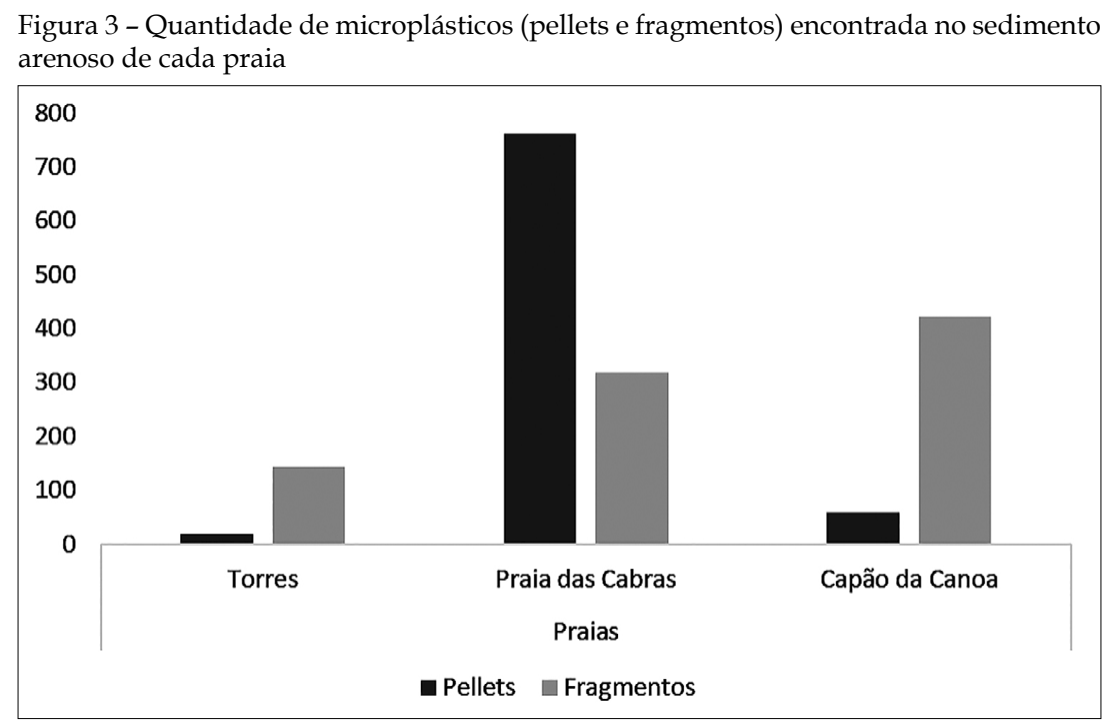

Embora as áreas densamente povoadas sejam reconhecidas como a principal fonte terrestre de contaminação por MPs, este estudo corrobora com outras pesquisas no mundo que apontam a presença deles em áreas sem intervenção humana. Para Alomar, Estarellas e Deudero (2016), os MPs são descartados direta ou indiretamente no mar através de águas residuais, redes de esgoto e escoamento terrestre, sendo esperado maiores concentrações de MPs em áreas urbanizadas, ao invés de áreas naturalmente intocadas. No entanto, em 
seu estudo, as maiores concentrações foram encontradas justamente nas duas praias não urbanizadas, situadas no Parque Nacional Marítimo-Terrestre do Arquipélago de Cabrera, indicando que esses resíduos são carreados para longe de sua fonte de origem e as áreas marinhas protegidas não estão livres da contaminação. Nesse contexto, Baztan et al. (2014) também constataram que todas as áreas amostradas nas Ilhas Canárias (Espanha) estão suscetíveis à poluição por MPs, inclusive em locais desabitados, como é o caso da Praia de Cochinos, localizada dentro do Parque Nacional de Timanfaya.

Quanto à presença de MPs na preamar e base das dunas, houve maior deposição de pellets na preamar para a Praia das Cabras (Figura 4). Para Capão da Canoa e Torres, a quantidade de MPs foi semelhante em ambas as regiões, e o número de fragmentos foi maior que o de pellets.

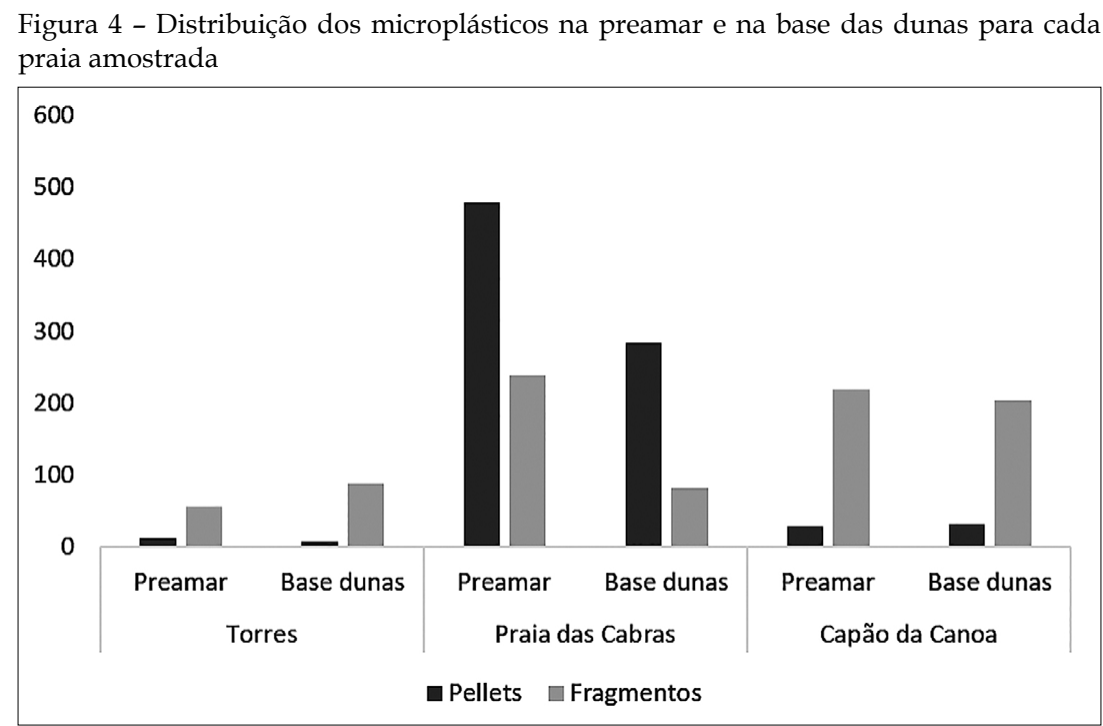

Dessa forma, os dados apresentados indicam que a Praia das Cabras parece ser favorável para o acúmulo de pellets, e o mar pode ser considerado a fonte principal para o encalhe das esférulas na praia, uma vez que o local possui reduzida ação antrópica. O Porto de Rio Grande (uma provável fonte emissora das esférulas) fica ao sul das áreas em estudo e, possivelmente, essas esférulas são carreadas para o norte pela deriva litorânea de sedimento, que é predominante de NE (Figueiredo \& Calliari, 2006), o que ajudaria a compreender a grande quantidade de pellets encontrada na Praia das Cabras. Da mesma forma, o estudo realizado por Pianowski (1997) verificou uma grande concentração desse material na praia pertencente ao Parque Nacional da Lagoa do Peixe, área próxima à Praia das Cabras e que também possui reduzida ação antrópica, numa média de 163,4 itens / m², provavelmente provenientes do Porto de Rio Grande. Costa et al. (2010) e Falcão e Souza (2014) consideram que a proximidade com zonas portuárias possa ter influência na dispersão e distribuição superficial de pellets nas praias. Quando nos oceanos, esses grânulos plásticos oriundos de portos e/ou efluentes industriais são carreados e podem viajar a longas distâncias e se depositar longe de sua fonte de origem (Manzano, 2009; Hirata et al., 2017).

Na Praia das Cabras observou-se grande quantidade de resíduos sólidos na faixa de areia, que, provavelmente, sejam provenientes do oceano, pois não há urbanização no local, o que eliminaria a entrada desses materiais pelos frequentadores. Por outro lado, 
pelo pouco tráfego de pessoas, a área pode ser utilizada como "bota-fora" e, justamente por não haver limpezas periódicas, o material vai se acumulando no local. Em um estudo realizado por Ferri (2012), ao analisar as concentrações de metais pesados em dois sangradouros na Praia de Cidreira e em outro ponto "controle" na Praia das Cabras, foram encontrados no último ponto valores semelhantes aos das áreas urbanizadas, levando a cogitar-se que a contaminação não seja proveniente somente do continente, mas também do oceano. Portanto, a Praia das Cabras, apesar de ser uma área não urbanizada e que teoricamente deveria apresentar menor impacto, denota a necessidade de maiores estudos para tentar compreender a dinâmica costeira nessa região.

Já para Capão da Canoa e Torres, sugere-se que a baixa concentração de pellets pode ter relação com as condições oceanográficas das praias, que não propiciam a deposição dessas esférulas. No entanto, devido à quantidade de fragmentos encontrados nessas praias, pode-se predizer que esses detritos chegam às praias tanto por fontes marinhas como por resíduos sólidos deixados nas praias, que, com o tempo, acabam se fragmentando, por causa da exposição a fatores físicos e químicos de degradação, e então são redistribuídos ao longo da praia pela ação dos ventos e das marés. Os MPs presentes nos oceanos, quando chegam à beira da praia, "se depositam primeiro na premar, uma área de caráter efêmero, dinâmico e sazonal" (Gregory, 2009; Baztan et al., 2014; Silva, P.P.G. e, 2016). Posteriormente, conforme o ciclo das marés, parte dos MPs que estão nessa região podem permanecer ou ser transportados para as dunas pela ação dos ventos, assim como a próxima maré poderá trazer mais MPs ou levar os acumulados de volta ao oceano. Eventos de tempestade também contribuem para a deposição desses materiais em camadas profundas do sedimento, e, conforme a morfodinâmica do ambiente, os MPs voltam à superfície, influenciando diretamente no seu padrão de distribuição (Falcão \& Souza, 2014; Turra et al., 2014).

Além disso, Torres é a única praia do litoral gaúcho que apresenta afloramentos rochosos, que lhe conferem proteção à dinâmica costeira, e é caracterizada como uma praia do tipo intermediária, de mobilidade moderada a alta e suscetível à erosão. Ao passo que Capão da Canoa encontra-se em estágio morfodinâmico dissipativo e intermediário, com mobilidade moderada a alta, e a Praia das Cabras, como intermediária e de baixa mobilidade, conforme Reichow (2018) e Calliari et al. (2006). Essas informações podem auxiliar na compreensão do motivo pelo qual em Torres ter sido encontrada a menor quantidade de MPs nas quatro coletas realizadas. A proteção e a morfologia praial podem diminuir a entrada de MPs na praia e/ou remover o sedimento arenoso juntamente com as partículas de plástico. No entanto, há outros fatores que podem influenciar o acúmulo de microplásticos. McWilliams, Liboiron e Wiersma (2018) recomendam que, em praias rochosas, outros protocolos de amostragem sejam adotados, visto que os resíduos podem estar localizados em maiores profundidades na areia. Para Pinheiro et al. (2019), na Praia de Boa Viagem (Recife, Brasil), a quantidade de microplásticos foi maior nas áreas protegidas por beachrocks do que em áreas expostas às ondas, podendo estar relacionado à menor hidrodinâmica da área. Esses beachrocks encontram-se paralelos à costa, diferindo dos promontórios rochosos presentes em Torres. Para os autores, é preciso considerar sua presença ao definir os locais de coleta de MPs.

Com base nos dados das triplicatas e no ajuste de linearidade dos dados, foi realizada análise estatística usando Anova para dois fatores (praia e região - marca da preamar e base das dunas), considerando o nível de significância de 5\%. Para a presença de pellets, 
na interação praia e região, há diferenças entre praias e não entre regiões, com P-valor bastante significativo (P-valor < 0,00023). O teste Post-hoc utilizando SNK mostrou que a presença de pellets na Praia das Cabras é diferente das outras duas praias (Capão da Canoa e Torres), que são iguais entre si (P-valor < 0,001). Do total de microplásticos coletados, a análise estatística confirmou o comportamento apresentado nas análises individuais de pellets e fragmentos, ou seja, há diferença na distribuição entre as praias (P-valor 0,003545). No entanto, foi a Praia de Torres que diferiu (para menos) das outras duas quanto à presença de MPs.

Os dados da análise estatística corroboram com a avaliação descritiva feita, onde o número expressivo de pellets, principalmente na Praia das Cabras, aponta para a necessidade de conhecimento da fonte de contaminação e que em Torres foi encontrada a menor quantidade de MPs. Nas três praias estudadas, não há fontes antropogênicas de contaminação por pellets, como emissários industriais e zonas portuárias. Somente em Torres há a desembocadura do Rio Mampituba, localizada ao norte da Praia Grande, que poderia ser uma fonte carreadora das esférulas para o mar. Entretanto, a deriva litorânea de sedimento é predominante de NE (Figueiredo \& Calliari, 2006), o que explicaria, caso os pellets sejam carreados pelo rio, o porquê de não serem encontrados em abundância em Torres, mas talvez ao norte da desembocadura, na praia em Passo de Torres.

\section{Influência da sazonalidade}

A presença de microplásticos foi avaliada quanto às quatro estações do ano (Figura 5), com o objetivo de verificar se a sazonalidade interfere na presença desses resíduos. A primavera foi a estação do ano que apresentou maior acúmulo (687 un.), seguida pelo inverno (462 un.) e verão (410 un.), enquanto no outono foram encontradas apenas 168 unidades.

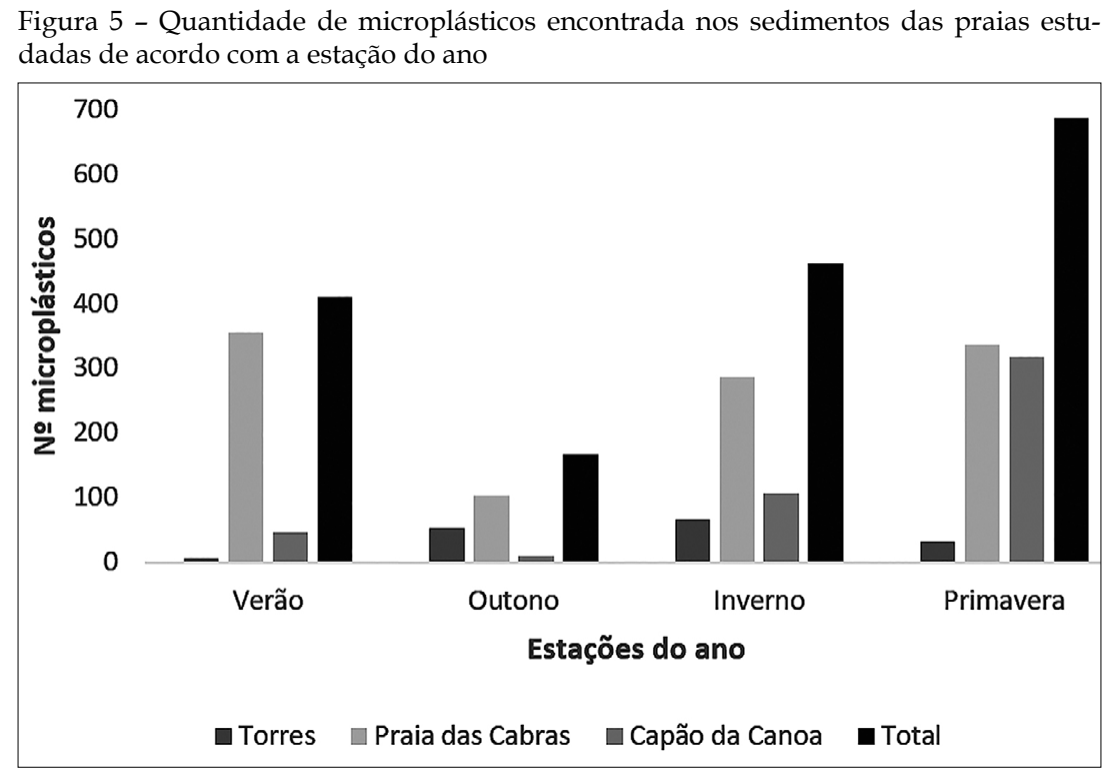

A Praia das Cabras apresentou maior abundância no verão e na primavera, totalizando 356 e 337 un., respectivamente. Já em Capão da Canoa, os valores mais expressivos foram na primavera e no inverno, com 317 e 117 un., respectivamente; em Torres, no outono/inverno, com 68 e 54 un. Em qualquer estação, a Praia das Cabras é a que obteve 
maior aporte de MPs. Dessa forma, nota-se que a distribuição dos MPs nos sedimentos arenosos não depende somente da sazonalidade; outros fatores devem influenciar a deposição desses materiais, como a orientação e a exposição de cada praia, a hidrodinâmica e o regime dos ventos (Kaberi et al., 2013; Kim, 2015; Silva, P.P.G. e, 2016). Paulo P. G. e Silva (2016), em um estudo realizado na Baía de Santos (São Paulo, Brasil), atribuiu à direção do vento, mas não à velocidade, a quantidade de MPs encontrados. De acordo com o autor, ventos predominantes de direção norte, noroeste e nordeste incidiram sobre a praia e contribuíram para o maior número de MPs nas praias.

Ao analisar a direção do vento, das ondas e a altura das ondas para as três praias estudadas durante as quatro estações do ano (Tabela I), observou-se que, nos três períodos de maior abundância de MPs (primavera, inverno e verão), a direção do vento variou de nordeste, oeste e sudoeste. Cabe destacar que na estação onde foram encontrados mais MPs (primavera) a direção dos ventos foi de sudoeste. A altura predominante das ondas durante as estações foi acima de 1 metro, exceto no outono, período com menor deposição de MPs. Dessa maneira, pode-se considerar que a altura das ondas influencia o acúmulo de MPs na preamar.

Tabela I - Condições oceanográficas para as três praias estudadas, conforme as estações do ano

\begin{tabular}{|c|c|c|c|c|}
\hline Coleta & Cidade & Direção vento & Ondulação (m) & Direção da onda \\
\hline \multicolumn{5}{|c|}{ Verão } \\
\hline 29/jan. & Torres & Sudoeste & 1,6 & Nordeste \\
\hline 31/jan. & Capão da Canoa & Nordeste & 1,8 & Sudeste \\
\hline 27/jan. & Praia das Cabras & Nordeste & 2,1 & Sudeste \\
\hline \multicolumn{5}{|c|}{ Outono } \\
\hline 30/abr. & Torres & Noroeste & 1,1 & Leste \\
\hline 29/abr. & Capão da Canoa & Nordeste & 0,9 & Leste \\
\hline 29/abr. & Praia das Cabras & Nordeste & 0,9 & Leste \\
\hline \multicolumn{5}{|c|}{ Inverno } \\
\hline 26/jul. & Torres & Nordeste & 2,7 & Leste \\
\hline 26/jul. & Capão da Canoa & Nordeste & 2,7 & Leste \\
\hline 6/ago. & Praia das Cabras & Oeste & 2 & Leste \\
\hline \multicolumn{5}{|c|}{ Primavera } \\
\hline 6/out. & Torres & Sudoeste & 2,8 & Sudeste \\
\hline 6/out. & Capão da Canoa & Sudoeste & 2,8 & Sudeste \\
\hline 6/out. & Praia das Cabras & Sudoeste & 2,8 & Sudeste \\
\hline
\end{tabular}

Fonte: Windy (2018).

Para Paulo P. G. e Silva (2016), a densidade média dos MPs é menor que a densidade dos grãos e, por isso, o vento auxilia tanto no transporte de grãos de areia nas praias quanto no transporte de partículas de plástico; assim como a velocidade necessária para o transporte de sedimento e das partículas de plástico irá depender do tamanho, da forma e da densidade do material (Browne et al., 2010). Danilo B. Silva (2016) indica que a entrada de MPs varia conforme a energia das ondas e os processos sedimentares, e o encalhe é "um processo pontual e o estoque permanente reflete uma contaminação crônica e de longo prazo". Ou seja, a energia das ondas irá afetar diretamente o aporte de MPs na praia. Fato comprovado nesta amostragem, pois, no outono, a energia das ondas foi pouco expressiva, não ultrapassando 1,1 m (Tabela I), e causou um menor acúmulo de MPs na preamar em todos os pontos. 
Embora Torres tenha apresentado maiores concentrações no outono, o número se deve à região da base das dunas, que apresentou 49 un. e apenas 5 un. na preamar (Figura 6). Da mesma forma, Hirata et al. (2017), em cinco pontos de coleta durante quatro dias de amostragem, coletaram 880 pellets, resultando, em média, que 220 pellets chegam por dia em uma área de $5 \mathrm{~m}^{2}$, e constataram que, durante o seu período de coleta, a agitação do mar estava fraca, com ondas inferiores a 1,5 m de altura. Já no estudo de Manzano (2009) na Enseada de Santos, houve um aumento significativo de deposição dessas esférulas no outono $\left(163\right.$ pellets $\left./ \mathrm{m}^{2}\right)$ e no inverno $\left(377\right.$ pellets $\left./ \mathrm{m}^{2}\right)$, devido à maior agitação do mar, provocada por ventos intensos na semana da coleta, e à menor deposição de MPs em condições de mar calmo, com pouco vento e agitação da água.

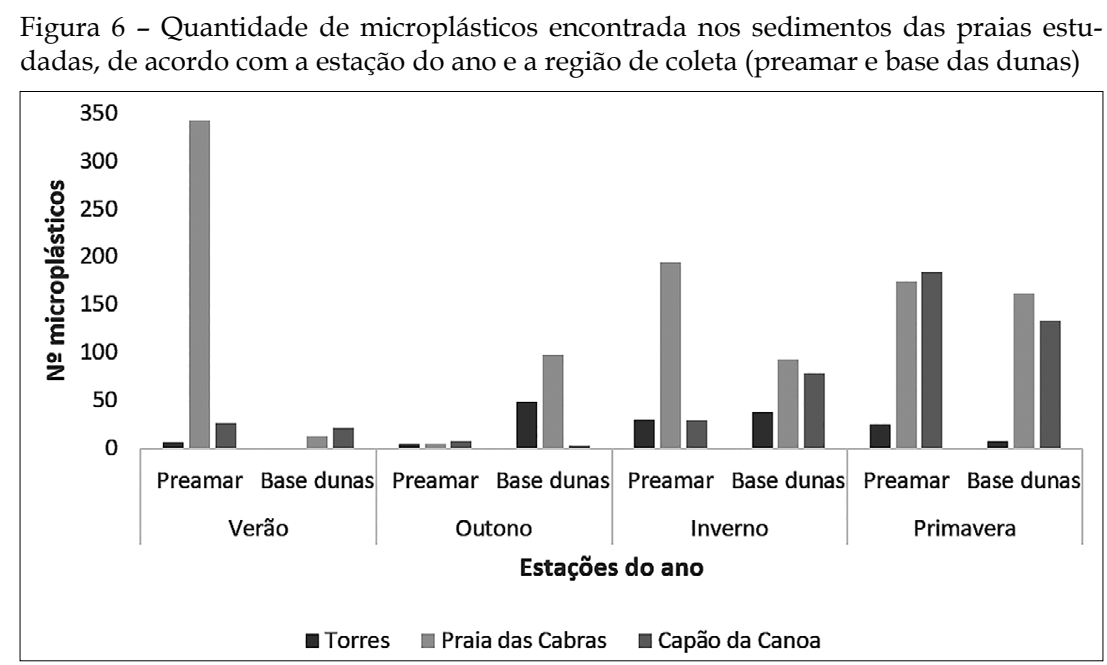

Outros mecanismos que podem afetar a quantidade de MPs encontrada são o pisoteio e a limpeza da areia pelos órgãos públicos, que acarretam o soterramento e a remoção dos MPs. Para Torres, cidade que recebe muitos veranistas durante a temporada, as menores concentrações foram no mês de janeiro e deve-se, possivelmente, a esses fatores. Em Capão da Canoa, praia que também recebe muitos turistas durante o verão, a coleta foi realizada pela manhã, antes da limpeza da areia pela prefeitura, e talvez possa explicar a quantidade de MPs encontrada mesmo nessa estação. Já para a Praia das Cabras, uma área que não há urbanização, exceto eventualmente no verão, foram encontradas as maiores quantidades de MPs nesse mesmo período. Manzano (2009) e Paulo P. G. e Silva (2016) relatam que concentrações de microplásticos em areias superficiais podem ser subestimadas, pois a maioria dos estudos são realizados em áreas urbanizadas, onde ocorre limpeza periódica dos locais. Pianowski (1997) e Hirata et al. (2017) também mencionam que em áreas menos acessíveis ao público não ocorre o soterramento dos MPs e por isso são encontrados com maior frequência. Portanto, o soterramento e as limpezas da praia podem ser um fator negativo para analisar as concentrações de MP no sedimento de praias em áreas urbanizadas, pois a deposição dessas partículas na preamar e na base das dunas não será avaliada caso a coleta seja realizada posteriormente à limpeza e ao uso da praia. 


\section{CONCLUSÃO}

Nas três praias estudadas, a poluição por microplásticos está presente e ocorreu ao longo das quatro estações do ano. A urbanização local não parece ser o fator predominante para a deposição de partículas de plástico a longo prazo, pois a maior quantidade foi encontrada justamente na Praia das Cabras, área em que há reduzida ação antrópica. Além disso, as análises estatísticas apontam que a diferença de distribuição de MPs ocorre entre as praias e não entre as regiões (preamar e base das dunas). A principal fonte de entrada para a Praia das Cabras provavelmente seja pelos oceanos, ressaltando a importância de considerar conjuntamente a dinâmica das ondas, correntes e marés para o aporte de MPs no sedimento das praias.

Os dados, principalmente da Praia das Cabras, evidenciam que a problemática dos pellets nos oceanos também é crescente, estando diretamente relacionada com a perda durante sua cadeia produtiva, desde a fabricação até o manuseio e transporte. A presente pesquisa aponta a fragilidade e a importância de preservar a zona costeira e marinha, sendo imprescindível maiores estudos sobre a origem e a dinâmica oceânica da região para compreender por que há um aporte tão grande de pellets nesse sedimento, mesmo não estando próxima de áreas portuárias ou industriais.

\section{REFERÊNCIAS BIBLIOGRÁFICAS}

Alencar, M.V.; Proietti, M.C. \& Rodrigues, F.L. Abundância e distribuição de microplásticos depositados na praia do Cassino, RS, p. 356-357, in Encontro Nacional de Gerenciamento Costeiro, Rio Grande, 396 p., 2017.

Alomar, C.; Estarellas, F. \& Deudero, S. Microplastics in the Mediterranean Sea: deposition in coastal shallow sediments, spatial variation and preferential grain size. Marine Environmental Research, v. 115, p. 1-10, 2016.

Andrade Neto, G.F. Ocorrência, distribuição e grau de poluição por pellets, lixo de praia e lixo bentônico nas praias do município de Salvador, Bahia, Brasil. Dissertação de mestrado, Universidade Federal da Bahia, 101 p., Salvador, 2014.

Andrady, A.L. Microplastics in the merine environment. Marine Pollution Bulletin, v. 62, p. 1596-1605, 2011.

Andrady, A.L. Persistence of plastic litter in the oceans, p. 57-72, in Bergmann, M.; Gutow, L. \& Klages, M., Marine Anthropogenic Litter. Springer, p. 456, Germany, 2015.

Andrady, A.L. The plastic in microplastic: a review. Marine Pollution Bulletin, v. 119, n. 1, p. 12-22, 2017.

Antunes, J.; Frias, J. \& Sobral, P. Microplastics on the portuguese coast. Marine Pollution Bulletin, v. 131, p, 294-302, 2018.

Arthur, C.; Baker, J. \& Bamford, H. Proceedings of the International Research Workshop on the Occurrence, Effects and Fate of Microplastic Marine Debris. NOAA Technical Memorandum NOS-ORER-30, p. 49, Maryland, 2009.

Avio, C.G.; Gorbi, S. \& Regoli, F. Plastics and microplastics in the oceans: from emerging pollutants to emerged threat. Marine Environmental Research, v. 128, p. 2-11, 2017. 
Barnes, D.K.A.; Galgani, F.; Thompson, R.C. \& Barlaz, M. Accumulation and fragmentation of plastic debris in global environments. Philosophical Transactions of the Royal Society B: Biological Sciences, v. 364, 1985-1998, 2009.

Baztan, J. et al. Protected areas in the Atlantic facing the hazards of micro-plastic pollution: first diagnosis of three islands in the Canary Current. Marine Pollution Bulletin, v. 80, p. 302311, 2014.

Brach, L.; Deixonne, P.; Bernard, M.F.; Durand, E.; Desjean, M.C.; Perez, E.; van Sebille, E. \& Ter Halle, A. Anticyclonic eddies increase accumulation of microplastic in the North Atlantic subtropical gyre. Marine Pollution Bulletin, v. 126, p. 191-96, 2018.

Brongersma, L. Notes upon some turtles from the Canary Islands and from Madeira. Proceedings of the Koninklijke Nederlandse Akademie van Wetenschappen Series C Biological and Medical Sciences, v. 71, n. 2, p.128-136, 1968.

Browne, M.A.; Galloway, T.S. \& Thompson, R.C. Spatial patterns of plastic debris along Estuarine Shorelines. Environmental Science E Technology, v. 44, n. 9, p. 3404-3409, 2010.

Caldwell, M.C.; Caldwell, D.K. \& Siebenaler, J.B. Observations on captive and wild Atlantic bottlenosed dolphins, Tursiops truncatus, in the northeastern Gulf of Mexico. Los Angeles County Museum Contributions in Science, Califórnia, n. 91, p. 2-10, 1965.

Calliari, L. et al. Classificação geomorfológica: Rio Grande do Sul, p. 438-475, in Muehe, D. (org.), Ministério do Meio Ambiente, Erosão e Progradação do Litoral Brasileiro, p. 476, Brasília, 2006.

Camedda, A.; Marra, A.; Matiddi, M.; Massaro, G.; Coppa, S.; Perilli, A.; Ruiu, A.; Briguglio, P. \& de Lucia, G.A. Interaction between loggerhead sea turtles (Caretta caretta) and marine litter in Sardinia (Western Mediterranean Sea). Marine Environmental Research, v. 100, p. 2532, 2014.

Carpenter, E.J. \& Smith, K.L. Plastics on the Sargasso Sea surface. Science, v. 175, n. 4027, p. $1240-124,1972$.

Castro, R.O.; Silva, M.L. \& Araújo, F.V. Review on microplastic studies in Brazilian aquatic ecosystems. Ocean and Coastal Management, v. 165, p. 385-400, 2018.

Cole, M. et al. Microplastic ingestion by zooplankton. Environmental Science Technology, v. 47, n. 12, p. 6646-6655, 2013.

Cole, M.; Lindeque, P.; Halsband, C. \& Galloway, T.S. Microplastics as contaminants in the marine environment: a review. Marine Pollution Bulletin, v. 62, n. 12, p. 2588-2597, 2011.

Coley, I.A. \& Verbel, J.O. Microplastic resin pellets on an urban tropical beach in Colombia. Environmental Monitoring and Assessment, v. 187, n. 435, 2015.

Costa, M.F. et al. On the importance of size of plastic fragments and pellets on the strandline: a snapshot of a Brazilian beach. Environmental Monitoring and Assessment, v. 168, p. 299-304, 2010.

Critchell, K. \& Lambrechts, J. Modelling accumulation of marine plastics in the coastal zone; what are the dominant physical processes? Estuarine, Coastal and Shelf Science, v. 171, p. 111-122, 2016. 
English, M.D. et al. Plastic and metal ingestion in three species of coastal waterfowl wintering in Atlantic Canada. Marine Pollution Bulletin, v. 98, n. 1-2, p. 349-353, 2015.

Falcão, M.P. \& Souza, C.R.G. Contribuições da geomorfologia costeira aos estudos sobre pellets de plástico em praias de SP, Brasil. Revista Geonorte, v. 10, n. 1, p. 71-76, 2014.

Ferri, P.L.F. Análises da qualidade da água proveniente de sangradouros localizados no município de Cidreira - litoral norte do Rio Grande do Sul, Brasil. Monografia, Instituto de Biociências, UFRGS/UERGS, 58 p., Imbé/Cidreira, 2012.

Figueiredo, S.A. \& Calliari, L.J. Sedimentologia e suas implicações na Morfodinâmica das praias adjacentes às desembocaduras da linha de costa do Rio Grande do Sul. Gravel, n. 4, p. 73-87, 2006.

Frias, J.P. et al. Standardised protocol for monitoring microplastics in sediments. JPI-Oceans BASEMAN Project, 24 p., 2018.

Galgani, F.; Hanke, G. \& Maes, T. Global distribution, composition and abundance of marine litter, p. 29-56, in Bergmann, M.; Gutow, L. \& Klages, M., Marine Anthropogenic Litter. Springer, 456 p., Germany, 2015.

Galgani, F.; Pham, C.K. \& Reisser. J. editorial: plastic pollution. Frontiers in Marine Science, v. 4, n. 307, 2017.

Gall, S.C. \& Thompson, R.C. The impact of debris on marine life. Marine Pollution Bulletin, v. 92, p. 170-179, 2015.

Geyer, R.; Jambeck, J.R. \& Law, K.L. Production, use, and fate of all plastics ever made. Science Advance, v. 3, n. 7, 2017.

Gomes, C.M.B. Lançamento de partículas de polietileno à costa do R.G.S. Véritas, Porto Alegre, v. 18, n. 70, p. 174-206, 1973.

Gregory, M.R. Environmental implications of plastic debris in marine settings entanglement, ingestion, smothering, hangers-on, hitch-hiking and alien invasions, Philosophical Transactions of the Royal Society B, v. 364, p. 2013-2025, 2009.

Hengstmann, E.; Tamminga, M.; vom Bruch, C. \& Fischer, E.K. Microplastic in beach sediments of the Isle of Rügen (Baltic Sea): implementing a novel glass elutriation column. Marine Pollution Bulletin, v. 126, p. 263-274, 2018.

Hirata, G. et al. Caracterização de pellets plásticos na Praia do Tombo, município do Guarujá, SP, Brasil. Revista Internacional de Ciências, v. 7, n. 2, p. 202-216, 2017.

Holgersen, H. Norske lomviers vandringer, Sterna, v. 4, p. 229-240, 1961.

Ivar do Sul, J.A. Contaminação ambiental por microplásticos em Fernando de Noronha, Abrolhos $e$ Trindade. Tese de doutorado, Programa de Pós-Graduação em Oceanografia, Universidade Federal de Pernambuco, 75 p., Recife, 2014.

Ivar do Sul, J.A.; Costa, M. \& Fillmann, G. Occurrence and characteristics of microplastics on insular beaches in the Western Tropical Atlantic Ocean. PeerJ Preprints, p. 1-11, 2017.

Jambeck, J.R. et al. Plastic waste inputs from land into the ocean. Science, v. 347, n. 6.223, p. 768-771, 2015. 
Kaberi, H. et al. Microplastics along the shoreline of a Greek island (Kea isl., Aegean Sea): types and densities in relation to beach orientation, characteristics and proximity to sources, p. 197-202, in 4th International Conference on Environmental Management, Engineering, Planning and Economics and SECOTOX Conference, 6 p., Mykonos, 2013.

Kim, I.S. et al. Factors influencing the spatial variation of microplastics on HighTidal Coastal Beaches in Korea. Archives of Environmental Contamination and Toxicology, n. 69, p. 299-309, 2015.

Law, K.L. Plastics in the marine environment. Annual Review of Marine Science, v. 9, p. 20529, 2017.

Lebreton, L.C.M. et al. River plastic emissions to the world's oceans. Nature Communication, v. 8, n. 15.611, 2017.

Lopes, E.B.; Ruiz, T.C.D. \& Anjos, F.A. A ocupação urbana no litoral norte do Rio Grande do Sul, Brasil, e suas implicações no turismo de segunda residência. Revista Brasileira de Gestão Urbana, v. 10, p. 426-441, 2018.

Lozoya, J.P. et al. Plastics and microplastics on recreational beaches in Punta del Este (Uruguay): unseen critical residentes? Environmental Pollution, v. 212, p. 931-941, 2016.

Lusher, A. et al. Microplastic and macroplastic ingestion by a deep diving, oceanic cetacean: the True's beaked whale Mesoplodon mirus. Environmental Pollution, v. 199, p. 185-191, 2015.

Macedo, F.S. et al. Distribuição e quantidades de microplásticos na orla da praia do Cassino, Rio Grande, RS, p. 168-169, in Encontro Nacional de Gerenciamento Costeiro, 681 p., Florianópolis, 2018.

Manzano, A.B. Distribuição, taxa de entrada, composição química e identificação de fontes de grânulos plásticos na Enseada de Santos, SP, Brasil. Dissertação de mestrado, Instituto Oceanográfico, Universidade de São Paulo, 124 p., São Paulo, 2009.

McWilliams, M.; Liboiron, M. \& Wiersma, Y. Rocky shoreline protocols miss microplastics in marine debris surveys (Fogo Island, Newfoundland and Labrador). Marine Pollution Bulletin, v. 129, p. 480-486, 2018.

Moore, C.J. Synthetic polymers in the marine environment: a rapidly increasing, long-term threat. Environmental Research, v. 108, p. 131-139, 2008.

Nel, H.A. et al. Do microplastic loads reflect the population demographics along the southern African coastline? Marine Pollution Bulletin, v. 15, p. 115-119, 2016.

Nicolau, L. et al. Ingestion of marine litter by loggerhead sea turtles, Caretta caretta, in portuguese continental waters. Marine Pollution Bulletin, v. 103, n. 1-2, p. 179-185, 2016.

Oliveira, L.P. et al. Monitoramento anual de um perfil de praia no litoral norte do Rio Grande do Sul (Praia das Cabras, Cidreira), in Anais do XVI Congresso da Associação Brasileira de Estudos do Quarternário, Bertioga, 2017.

Ory, N.C. et al. Amberstripe scad Decapterus muroadsi (Carangidae) fish ingest blue microplastics resembling their copepod prey along the coast of Rapa Nui (Easter Island) in the South Pacific subtropical gyre. Science of the Total Environment, v. 586, p. 430-437, 2017. 
Peeken, I. et al. Arctic sea ice is an important temporal sink and means of transport for microplastic. Nat. Commun., v. 9, n. 1505, 2018.

Pham, C.K. et al. Plastic ingestion in oceanic-stage loggerhead sea turtles (Caretta caretta) off the North Atlantic subtropical gyre. Marine Pollution Bulletin, v. 121, n. 1-2, p. 222-229, 2017.

Pianowski, F. Resíduos sólidos e esférulas plásticas nas praias do Rio Grande do Sul - Brasil. Monografia, Departamento de Oceanografia, FURG, 79 p., Rio Grande, 1997.

Pinheiro, L.M. et al. Do beachrocks affect microplastic deposition on the strandline of sandy beaches? Marine Pollution Bulletin, v. 141, p. 569-572, 2019.

Plastics Europe. Plastics - the facts 2018: an analysis of European plastics production, demand and waste data, 60 p., Bélgica, 2018.

Portz, L.; Manzolli, R.P. \& Ivar do Sul, J.A. Marine debris on Rio Grande do Sul north coast, Brazil: spatial and temporal patterns. Journal of Integrated Coastal Zone Management, v. 11, p. 41-48, 2011.

Reichow, C. A barreira costeira holocênica e suas relações com a morfodinâmica praial no estado do Rio Grande do Sul, Brasil. Dissertação de mestrado, Programa de Pós-Graduação em Geociências, UFRGS, 77 p., Porto Alegre, 2018.

Reisser, J. et al. Millimeter-sized marine plastics: a new pelagic habitat for microorganisms and invertebrates. Plose One, v. 9, n. 6, 2014.

Rigon, C.T. Análise da ingestão de resíduos sólidos e impactos no trato gastrointestinal em juvenis de Chelonia mydas (Linnaeus, 1758) no litoral norte e médio leste do Rio Grande do Sul, Brasil. Monografia, Universidade Federal do Rio Grande do Sul, 66 p., Imbé, 2012.

Ryan, P.G. How quickly do albatrosses and petrels digest plastic particles? Environmental Pollution, v. 207, p. 438-440, 2015.

Santos, I.R. et al. Geração de resíduos sólidos pelos usuários da praia do Cassino, RS, Brasil. Gerenciamento Costeiro Integrado, p. 12-14, 2004.

Silva, D.B. Spatial distribution, input and dispersion of plastic pellets in coastal zones. Tese de doutorado, Instituto Oceanográfico, Universidade de São Paulo, 156 p., São Paulo, 2016.

Silva, P.P.G. e. Contaminação e toxicidade de microplásticos em uma área de proteção marinha e costeira. Dissertação de mestrado, Programa de Pós-Graduação e Área de Concentração em Ciências da Engenharia Ambiental, Escola de Engenharia de São Carlos, Universidade de São Paulo, 85 p., São Carlos, 2016.

Tomazelli, L.J. \& Villwock, J.A. Considerações sobre o ambiente praial e a deriva litorânea de sedimentos ao longo do litoral norte do Rio Grande do Sul, Brasil. Pesquisas em Geociências, v. 19, n. 1, p. 3-12, 1992.

Tourinho, P.S. Ingestão de resíduos sólidos por juvenis de tartaruga-verde (Chelonia mydas) na costa do Rio Grande do Sul, Brasil. Monografia, Universidade Federal do Rio Grande, Rio Grande, RS, Brasil, 44 p., 2007.

Turra, A. et al. Three-dimensional distribution of plastic pellets in sandy beaches: shifting paradigms. Scientific Reports, v. 4, p. 4435, 2014. 
Van Cauwenberghe, E.; Devriese, L.; Galgani, F.; Robbens, J. \& Janssen, C.R. Microplastics in sediments: a review of techniques, occurrence and effects. Marine Environmental Research, v. 111, p. 5-17, 2015.

Waller, A.; Griffiths, H.J.; Waluda, C.M.; Thorpe, S.E.; Loaiza, I.; Moreno, B.; Pacherres, C.O. \& Hughes, K.A. Microplastics in the Antarctic marine system: an emerging area of research. Science of the Total Environment, v. 598, p. 220-227, 2017.

Wilcox, C.; Van Sebille, E. \& Hardesty, B.D. Threat of plastic pollution to seabirds is global, pervasive, and increasing. Proceedings of the National Academy of Sciences of U.S.A., Santa Cruz, v. 112, n. 38, p. 11899-11904, 2015.

Windy. Disponível em: https: www.windy.com. Acesso em: 23 out. 2018.

Wright, L.D. \& Short, A.D. Morphodynamic variability of surf zones and beaches: a synthesis. Marine Geology, v. 56, p, 93-118, 1984.

Zarzur, S. Alimentação e ingestão de plásticos nos Procellariiformes (albatrozes e petréis) encontrados na Praia do Cassino. Monografia, Universidade Federal do Rio Grande, Rio Grande, RS, Brasil, 1995.

Ziajahromi, S.; Neale, P.A.; Rintoul, L. \& Leusch, F.D.L. Wastewater treatment plants as a pathway for microplastics: development of a new approach to sample wastewater-based microplastics. Water Research, v. 1, p. 93-99, 2017.

Zuanazzi, P.T. \& Bartels, M. Estimativas para a população flutuante do litoral norte do RS. Fundação de Economia e Estatística, Porto Alegre, 28 p., 2016. 